\title{
Evaluation of Ion Exchange Materials in K Basin Floor Sludge and Potential Solvents for PCB Extraction from Ion Exchange Materials
}
A. J. Schmidt
G. S. Klinger
P. R. Bredt

January 1998

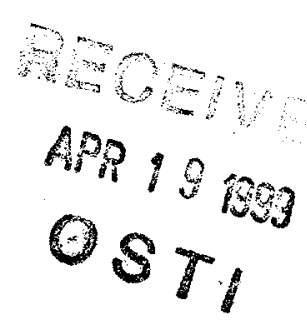

Prepared for the U.S. Department of Energy under Contract DE-AC06-76RLO 1830

Pacific Northwest National Laboratory

Richland, Washington 99352 


\title{
DISCLAIMER
}

This report was prepared as an account of work sponsored by an agency of the United States Government. Neither the United States Government nor any agency thereof, nor Battelle Memorial Institute, nor any of their employees, makes any warranty, express or implied, or assumes any legal liability or responsibility for the accuracy, completeness, or usefulness of any information, apparatus, product, or process disclosed, or represents that its use would not infringe privately owned rights. Reference herein to any specific commercial product, process, or service by trade name, trademark, manufacturer, or otherwise does not necessarily constitute or imply its endorsement, recommendation, or favoring by the United States Government or any agency thereof, or Battelle Memorial Institute. The views and opinions of authors expressed herein do not necessarily state or reflect those of the United States Government or any agency thereof.

\author{
PACIFIC NORTHWEST NATIONAL LABORATORY \\ operated by \\ BATTELLE \\ for the \\ UNITED STATES DEPARTMENT OF ENERGY \\ under Contract DE-AC06-76RLO 1830
}

Printed in the United States of America

Available to DOE and DOE contractors from the

Office of Scientific and Technical Information, P.O. Box 62, Oak Ridge, TN 37831;

prices available from (615) 576-8401.

Available to the public from the National Technical Information Service, U.S. Department of Commerce, 5285 Port Royal Rd., Springfield, VA 22161

This document was printed on recycled paper. 


\section{DISCLAIMER}

Portions of this document may be illegible in electronic image products. Images are produced from the best available original document. 


\section{Acknowledgments}

The authors would like to thank S. P. Burke, V. L. Hoefer, and J. D. Mathews for providing historical process information on $\mathrm{K}$ Basin operations. 


\section{Contents}

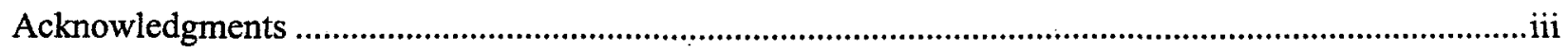

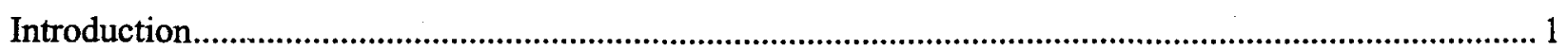

Ion Exchange Materials ............................................................................................. 1

Solvent Washing (Extraction) Studies with K Basin Sludge Simulant ........................................ 2

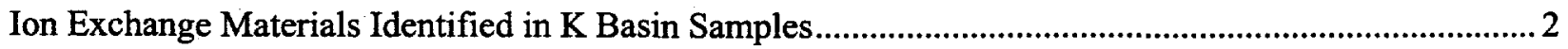

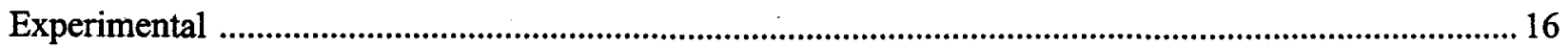

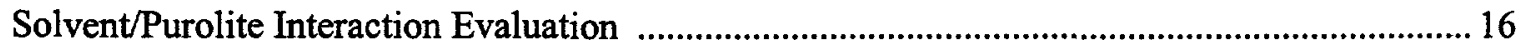

Inorganic Ion Exchanger (Zeolon-900) Behavior in Water .................................................. 16

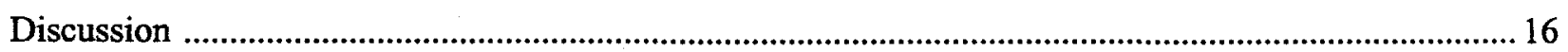

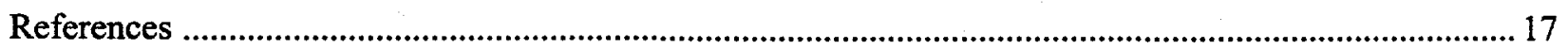




\section{Figures}

1 Resin beads separated from sample KES-H-08 by wet sieving technique. Sieve openings ore $0.355 \mathrm{~mm}$.

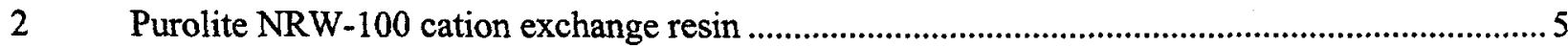

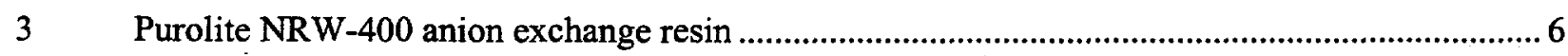

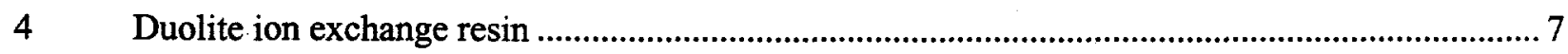

5 Purolite NRW-400 anion exchange resin and NRW-100 cation exchange resin in 1,1,1-Trichloroethane 8

6 Purolite NRW-400 anion exchange resin and NRW-100 cation exchange resin in Carbon Tetrachloride 9

7 Purolite NRW-400 anion exchange resin and NRW-100 cation exchange resin in 1,1,2-Trichloro-1,2,2-trifluoroethane

$8 \quad$ Purolite NRW-400 anion exchange resin and NRW-100 cation exchange resin in Methylene Chloride

9 Purolite NRW-400 anion exchange resin and NRW-100 cation exchange resin in pentane

10 Purolite NRW-400 anion exchange resin and NRW-100 cation exchange resin in toluene.

11 Purolite NRW-400 anion exchange resin and NRW-100 cation exchange resin in xylenes

12 Zeolon-900 in deoinized water 15

\section{Tables}

1 Weight Percent Dry Solids Separated During Sieving Analysis of KES-H-08 .3

2 Solvents Evaluated for Extraction Effectiveness 16 


\section{Introduction}

Approximately $73 \mathrm{~m}^{3}$ of heterogeneous solid material, "sludge," (upper bound estimate, Packer 1997) have accumulated at the bottom of the $\mathrm{K}$ Basins in the $100 \mathrm{~K}$ Area of the Hanford Site. This sludge is a mixture of spent fuel element corrosion products, ion exchange materials (organic and inorganic), graphite-based gasket materials, iron and aluminum metal corrosion products, sand, and debris (Makenas et al. 1996, 1997). In addition, small amounts of polychlorinated biphenyls (PCBs) have been found. These small amounts are significant from a regulatory standpoint. Ultimately, it is planned to transfer the $\mathrm{K}$ Basins sludge to the Hanford double shell tanks (DSTs). Chemical pretreatment is required to address criticality issues and the destruction or removal of PCBs before the K Basin sludge can be transferred to the DSTs.

Eleven technologies have been evaluated (Papp 1997) as potential pretreatment methods. Based on the evaluations and engineering studies and limited testing, Fluor Daniel Hanford recommended solvent washing of the K Basin sludge, followed by nitric acid dissolution and, potentially, peroxide addition (FDH 1997). The solvent washing (extraction) and peroxide addition would be used to facilitate PCB removal and destruction. Following solvent extraction, the PCBs could be distilled and concentrated for disposal as a low-level waste.

The purpose of the work reported here was to continue investigating solvent extraction, first by better identifying the ion exchange materials in the actual sludge samples and then evaluating various solvents for removing the PCBs or possibly dissolving the resins. This report documents some of the process knowledge on ion exchange materials used and spilled in the $\mathrm{K}$ Basins and describes the materials identified from wet sieving $\mathrm{KE}$ Basin floor and canister sludge and the results of other analyses. Several photographs are included to compare materials and illustrate material behavior. A summary of previous tests on solvent extraction of PCB surrogates from simulant $\mathrm{K}$ Basin sludge is also given.

\section{Ion Exchange Materials}

Over the years, the basin waters have been treated by ion exchange to lower radioactivity levels and associated radiolytic dose rates. Occasional losses of ion exchange media to the basins occurred, as evidenced by historical process knowledge and the results of $\mathrm{K}$ Basin sludge characterization.

$\mathrm{KE}$ Basin began receiving shipments of spent $\mathrm{N}$ Reactor fuel in 1975. As the spent fuel inventory grew, radioactive contamination and exposure levels increased. Steps were then taken to mitigate this situation, including installation of an ion exchange system (Gerber, 1996). Based on K Basin staff opinions and knowledge, it is believed that from 1978 to 1986 , zeolyte (specifically Zeolon 900), a cesium specific ion exchange material, was used in the $\mathrm{KE}$ Basin.

As a result of lessons learned in the KE Basin, the KW Basin was outfitted with an ion exchange system by the time it began receiving spent N Reactor fuel in 1981 (Gerber 1996). K Basins staff believe that from 1981 to 1986, and possibly later, a Duolite mixed bed was used at the KW Basin. The K Basins staff provided no specific information on the type of Duolite used.

From 1986 to the present time, the ion exchange modules (IXMs)/columns in KE and KW Basins have been loaded with and organic mixed bed resin. From 1993 (and perhaps even earlier) to the present, Purolite NRW-37 has been used as the mixed organic bed resin.

According to $\mathrm{K}$ Basin personnel, there is knowledge of four screen failures in the ion exchange columns (IXCs) that occurred during the KE Basin Fuel segregation campaign (1983/1984). When the screens failed, the entire contents of the IXCs were flushed to the Discharge Chute. Each failed screen released approximately $5 \mathrm{ft}^{3}$ of zeolite (Zeolon 900 ) for a total of approximately $20 \mathrm{ft}^{3}\left(0.57 \mathrm{~m}^{3}\right)$. It is possible that additional releases of zeolite also occurred. The material in the Discharge Chute was later pumped into the 
Weasel Pit in 1994 (i.e., before the KE floor and Weasel Pit sampling and characterization effort, which occurred in August and September 1995). Based on the cross-sectional area of the Weasel Pit $\left(10.6 \mathrm{~m}^{2}\right)$, the zeolite from the screen failures $\left(0.57 \mathrm{~m}^{3}\right)$, if uniformly distributed, could be visualized as forming a layer about $5 \mathrm{~cm}$ in depth in the Weasel Pit if the zeolite was the only material pumped in from the Discharge Chute at that time. On a volumetric basis, the zeolite would make up approximately $5 \%$ of the total sludge volume in the Weasel Pit (based on the $12.1 \mathrm{~m}^{3}$ upper bound sludge volume estimate, Packer 1997). When last measured in 1995 , the sludge depths in the Weasel Pit ranged from 30 to $90 \mathrm{~cm}$.

Although no process knowledge was uncovered that indicated Purolite organic resin beads were released into the basins, spherical resin beads were observed during wet sieving tests conducted with $\mathrm{KE}$ floor, Weasel Pit, and KE canister sludge samples (Silvers 1997; Makenas et al. 1997). Such beads were also noted lodged on top of spent fuel in KE near where beads were found on the KE Basin floor (Pitner 1995). As discussed above, $\mathrm{K}$ Basin records point to the use of mixed bed ion exchangers, in particular, Purolite NRW-37 Nuclear Grade Mixed Bed Resin.

\section{Solvent Washing (Extraction) Studies with K Basin Sludge Simulant}

Solvent washing tests with $\mathrm{KE}$ Basin simulant sludge were performed to examine the efficacy of $\mathrm{PCB}$ removal (using PCB surrogates) (Pool and Mong 1997). In the course of the testing with hexane and chloroform (trichloromethane), Pool and Mong found that only $60 \%$ to $70 \%$ of the PCB surrogate (trichlorobenzene) was removed from the $\mathrm{K}$ Basin composite sludge simulant, which among other constituents, contained $5.8 \mathrm{~g} / \mathrm{L}$ Duolite $\mathrm{C}-3$ resin powder, a resin readily available and similar to Duolite ARC-359. To investigate the factors contributing to these low recoveries, Pool and Mong conducted tests using some of the individual components in the simulant, including tests with Duolite only. The tests with Duolite showed that only $32 \%$ of the PCB surrogate was recovered after three contacts with hexane and one contact with chloroform. These findings suggested that if solvent extraction is to be considered for removing PCBs from $\mathrm{K}$ Basin sludge, different solvents may be necessary, depending upon which constituents PCBs are associated with in the actual sludge. Furthermore, photographs of sieved $\mathrm{KE}$ floor sludge did not provide any evidence that the Duolite ion exchange material used by Pool and Mong (1997) is present in the KE Basin sludge. Additionally, any further solvent washing testing should also consider the impacts of the presence of Purolite NRW 37 ion exchange resin on PCB removal, since it has been found in the KE Basin sludge.

\section{Ion Exchange Materials Identified in K Basin Samples}

Wet sieving has been performed on a select set of $\mathrm{K}$ Basin sludge samples. Sieving is a technique by which particles within a material can be separated into unique particle size fractions using meshes or perforated membranes. In wet sieving, an aqueous fluid (e.g. canister decant water) is introduced on top of the material. The fluid aids in the transport of the particles from one mesh to the next. During wet sieving of $\mathrm{K}$ Basin sludge samples, ion exchange beads have been found in KE Basin floor sludge (Sample KES-H-08 - near the North Load Out Pit), the Weasel Pit sludge (Sample KES-T-20), and in the KE canister sludge (Samples 96-06 and 96-11; both samples from canisters located close to the North Load Out Pit). A very high concentration of ion exchange beads was found in Sample KES-H-08. No ion exchange beads were found in KW canister sludge.

For the wet sieving tests (Silvers 1997), the K East Basin floor sample, KES-H-08, was passed through a series of Tyler screens with the fines being collected in a receiver vessel, and the dry weight percent recovered was determined (Table 1 ). The wt $\%$ dry solids was calculated by dividing the dry mass of the material retained on the screens or receiver by the sum of the masses of all the dry material in all the sieves and the receiver from the original sample. 
Table 1. Weight Percent Dry Solids Separated During Sieving Analysis of KES-H-08 (Silvers 1997)

\begin{tabular}{|c|c|c|c|}
\hline \multicolumn{3}{|c|}{ Screen Size } & $\begin{array}{l}\text { Sludge Retained on } \\
\text { Screen, wt\% (dry) }\end{array}$ \\
\hline Tyler Screen Size & U.S.A. Equivalent Size & $\begin{array}{l}\text { Sieve Opening } \\
(\mathbf{m m})\end{array}$ & 0 \\
\hline 6 & 6 & 3.35 & 0 \\
\hline 8 & 8 & 2.36 & 3 \\
\hline 14 & 16 & 1.18 & 66 \\
\hline 24 & 25 & 0.710 & 23 \\
\hline 42 & 45 & 0.355 & 8 \\
\hline Receiver (fines) & Receiver (fines) & $<0.355$ & \\
\hline
\end{tabular}

From observations, combined with the dry weight percent data, KES-H-08 appears to be approximately $90 \%$ resin beads. The manufacturer's specifications for Purolite NRW-37 Nuclear Grade Mixed Bed Resin, used at K East and K West Basins, indicate it is between 15 and 40 mesh (Tyler U.S. Standard) with less than $5 \%$ greater than $1.2 \mathrm{~mm}$ and under $2 \%$ less than $0.4 \mathrm{~mm}$. This size range approximately matches the beads collected from $\mathrm{K}$ East canister sludge and floor and Weasel Pit sludge (Figure 1).

Purolite NRW-37 consists of $40 \%$ by volume NRW- 100 cation exchange resin and $60 \%$ by volume Purolite NRW-400 anion exchange resin (see Figures 2 and 3). The anion resin is initially amber in color, and is a hydroxyl form trimethylamine functionalized polystryrene-divinyl benzene copolymer (Harland 1994; Sengupta 1995). The cation resin is initially nearly black in color, and is the hydrogen form sulfonic acid functionalized polystryrene-divinyl benzene copolymer (Harland 1994; Sengupta 1995). Samples of Purolite NRW-400 and NRW-100 were used for the solvent washing/extraction tests discussed here.

Hanford Site records document the use of Duolite ARC-359, a methylene sulfonic acid functionalized formal phenolic resin. Duolite is produced as a sheet that is then crushed and sieved to obtain the desired particle size. The irregular-shaped resin particles are displayed in Figure 4 for comparison with the resin beads separated from KES-H-08. No evidence of the presence of Duolite has been found to date during characterization of K Basins sludges. However, the KW Basins floors and pits have not yet been sampled or characterized. (Process knowledge indicates that some type of Duolite was used in the KW Basins.) Duolite ARC-359 was not examined in this work.

$\mathrm{K}$ Basin staff knowledge supports that an inorganic ion exchange material, zeolyte (Zeolon-900), is present in the KE Basin sludge. Zeolon-900 is an inorganic ion exchange material, which is gray in color and supplied as an extrudate approximately $2 \mathrm{~mm}$ in diameter by 2 to $10 \mathrm{~mm}$ in length. The chemical structure of Zeolon-900 (mordenite) is $\mathrm{Na}_{8}\left[\left(\mathrm{AlO}_{2}\right)_{8}\left(\mathrm{SiO}_{2}\right)_{40}\right] * 24 \mathrm{H}_{2} \mathrm{O}$ (Harland 1994). This material is friable and can potentially disintegrate into fine clay: Figure 12 is a photograph of Zeolon-900 after soaking in water for a period of time. Based on X-ray diffraction (XRD) data on the KE floor sludge (Makenas et al. 1996), a crystalline phase $\left(\mathrm{Na}_{2} \mathrm{O} \bullet \mathrm{Al}_{2} \mathrm{O}_{3} \bullet \mathrm{SiO}_{2} * \mathrm{H}_{2} \mathrm{O}\right)$ was identified in one sample (KES-H-08). On January 16, 1998, a vendor sample of Zeolon- 900 was analyzed via $\mathrm{XRD}$, and the same phase was observed (i.e., $\mathrm{Na}_{2} \mathrm{O} \bullet \mathrm{Al}_{2} \mathrm{O}_{3}$ - $\mathrm{SiO}_{2} \cdot \mathrm{H}_{2} \mathrm{O}$ ). This phase was identified as a type of mordenite. In sample KES-Q-17 (KE Weasel Pit sample), a phase $\mathrm{CaAl}_{2} \mathrm{Si}_{2} \mathrm{O}_{8} \bullet 4 \mathrm{H}_{2} \mathrm{O}$, gismodine was identified via XRD. Gismodine is a type of zeolite. Although other samples from the Weasel Pit were analyzed via XRD, no additional phases indicative of mordinite or zeolite were found. The lack of further evidence of the presence of zeolite in the Weasel Pit could have resulted from a number of factors, including the following: 1) the projected concentration of zeolite (5\%) is near the detection level for XRD; 2) the zeolite may be concentrated in an area in the Weasel Pit that was not sampled (due to physical restrictions, no samples were collected in the far east end of the Weasel Pit); 3) the zeolite may have undergone dissolution and reprecipitation reactions; 4) zeolite fines may have passed through the screen at the west end of the Weasel Pit and back into the basin; and/or 5) there may have been un-noted sludge transfers (i.e., pumping sludge to other areas). 


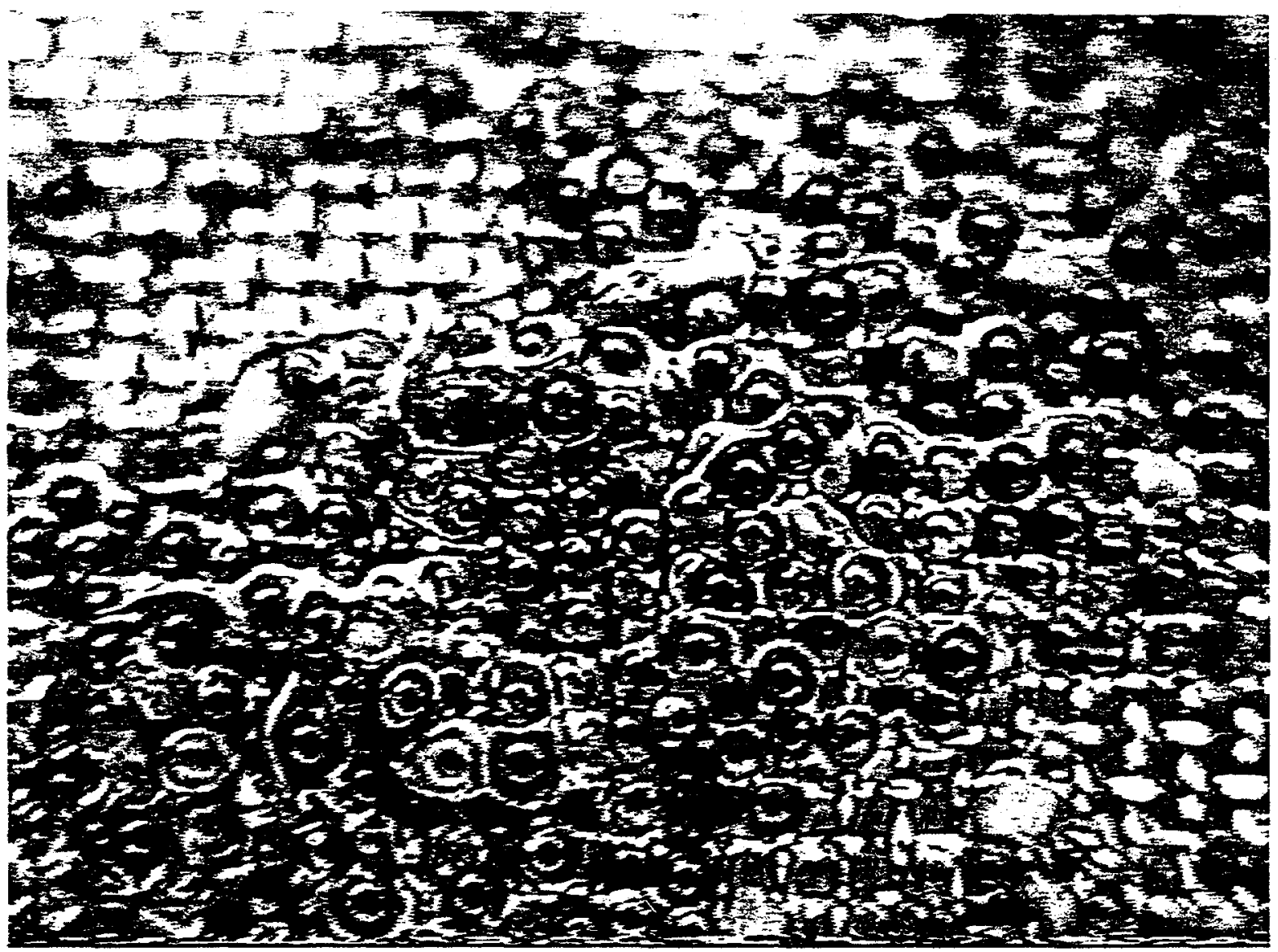

Figure 1. Resin beads separated from sample KES-H- 08 by wet sieving technique. Sieve openings are $0.355 \mathrm{~mm}$. Note in this photo several white particulates that do not appear to be resin beads but are similar in size. 


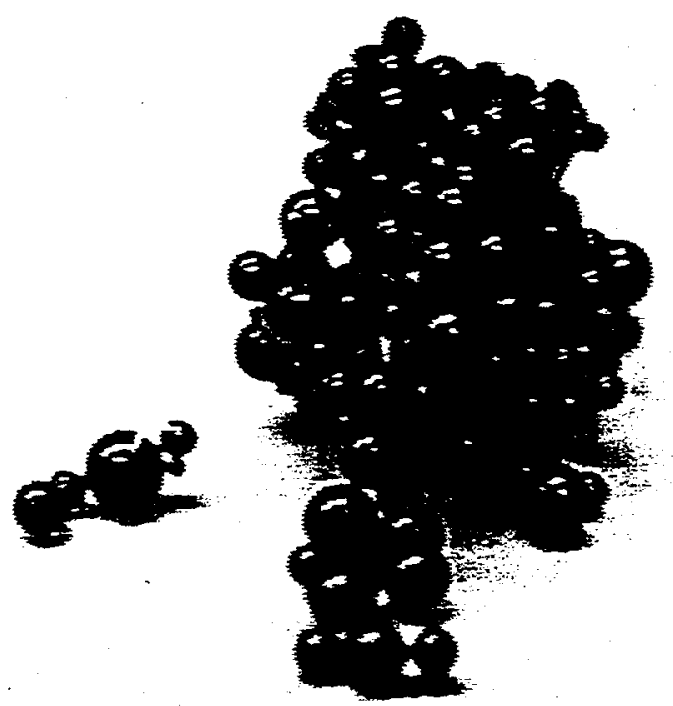

Figure 2. Purolite NRW-100 cation exchange resin. Beads are dark red to black in color and spherical. 


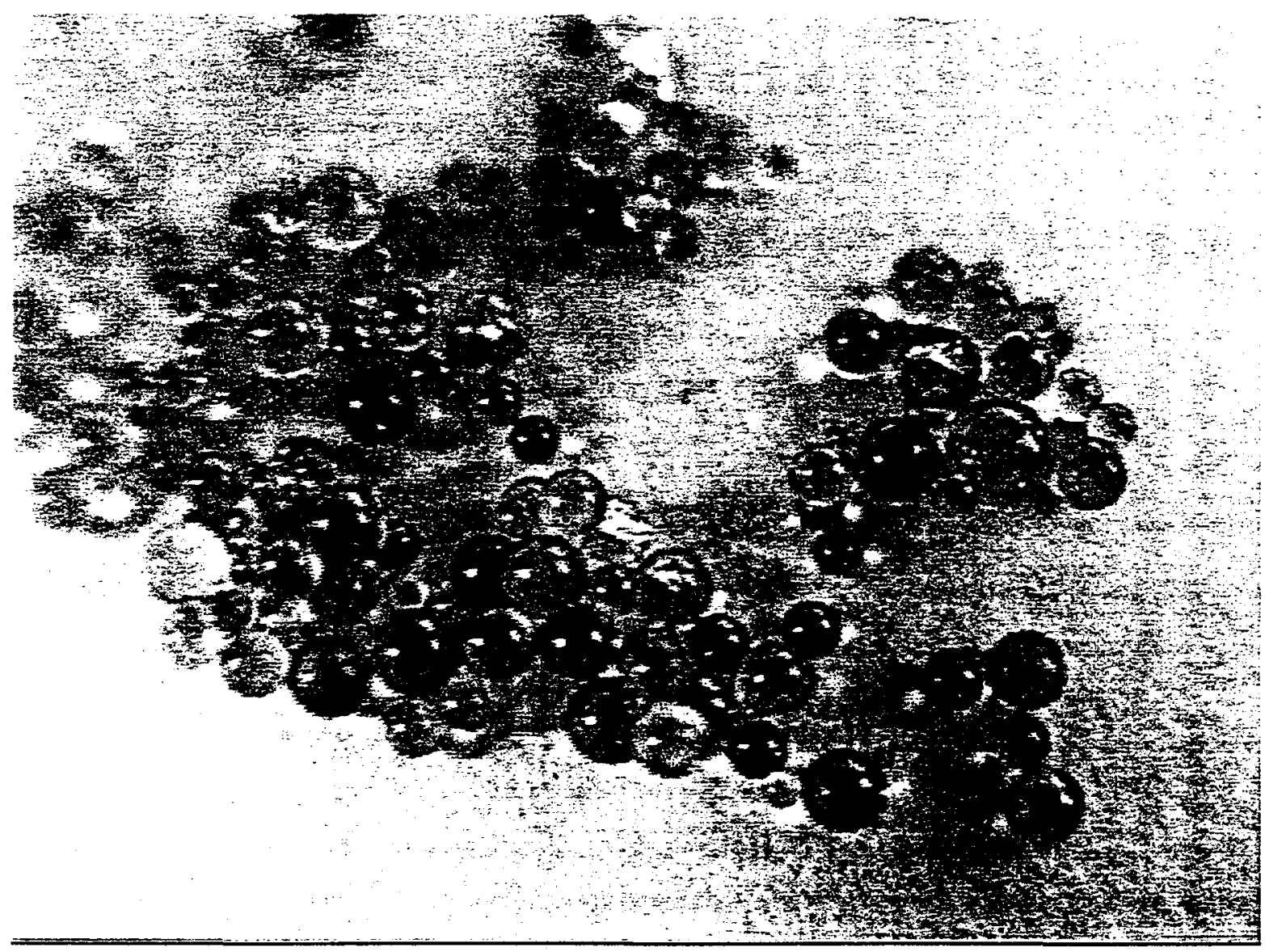

Figure 3. Purolite NRW-400 anion exchange resin. Beads are amber to light green in color and spherical. 


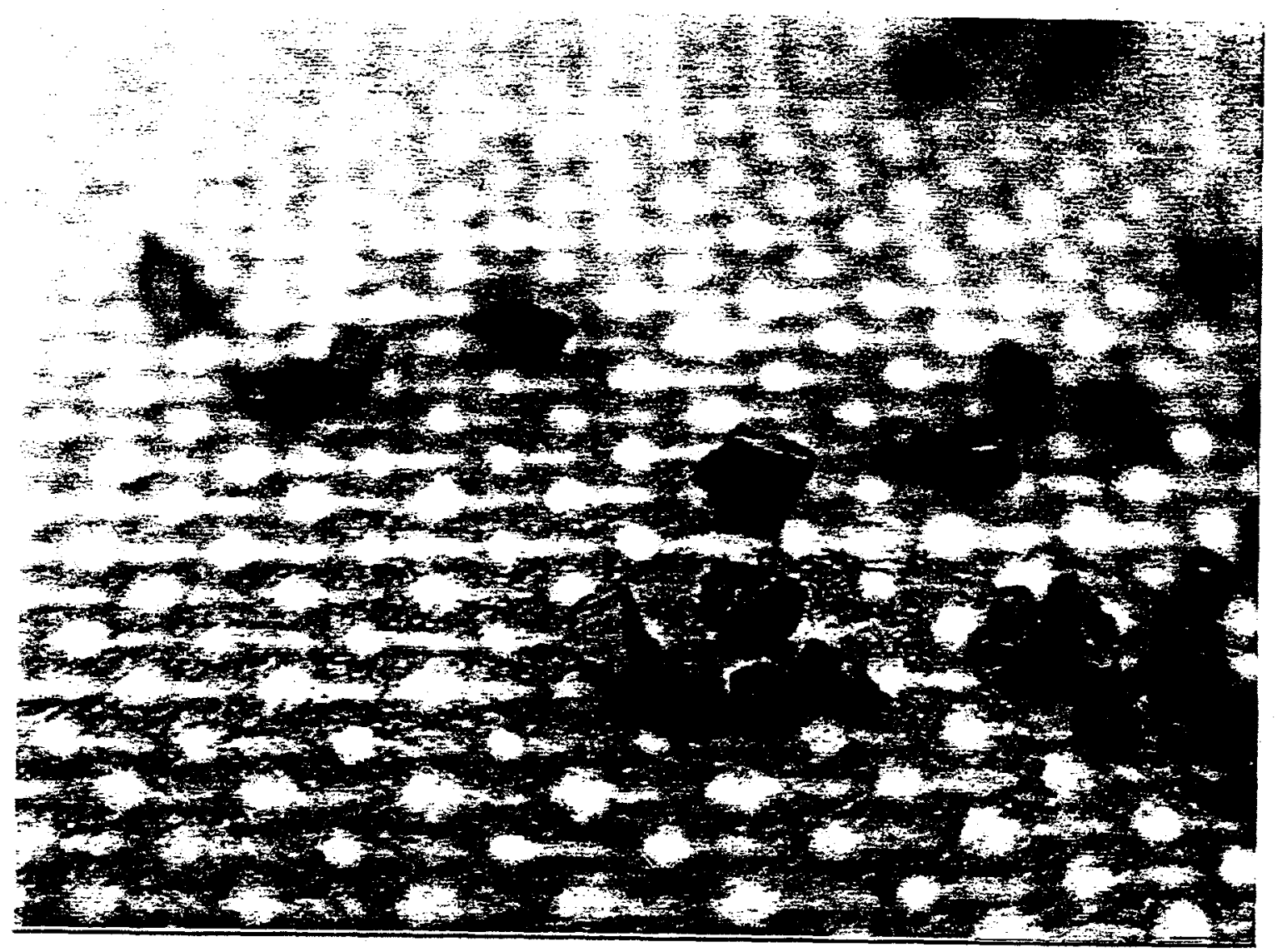

Figure 4. Duolite ion exchange resin. Beads are black in color and irregularly shaped. 


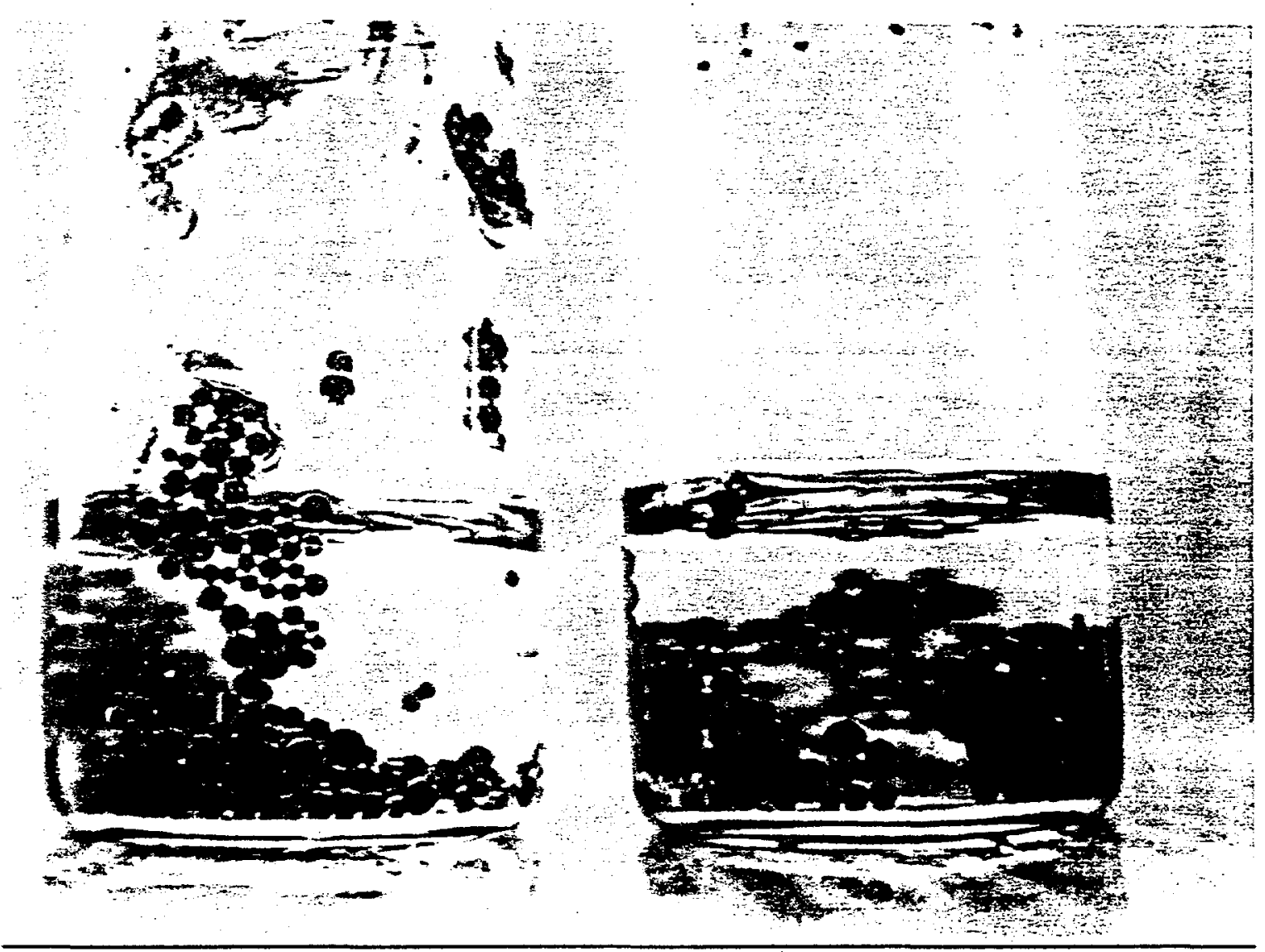

Figure 5. Purolite NRW-400 anion exchange resin (left), and NRW-100 cation exchange resin (right) in 1,1,1-Trichloroethane. Note the reddish color of the anion beads. 


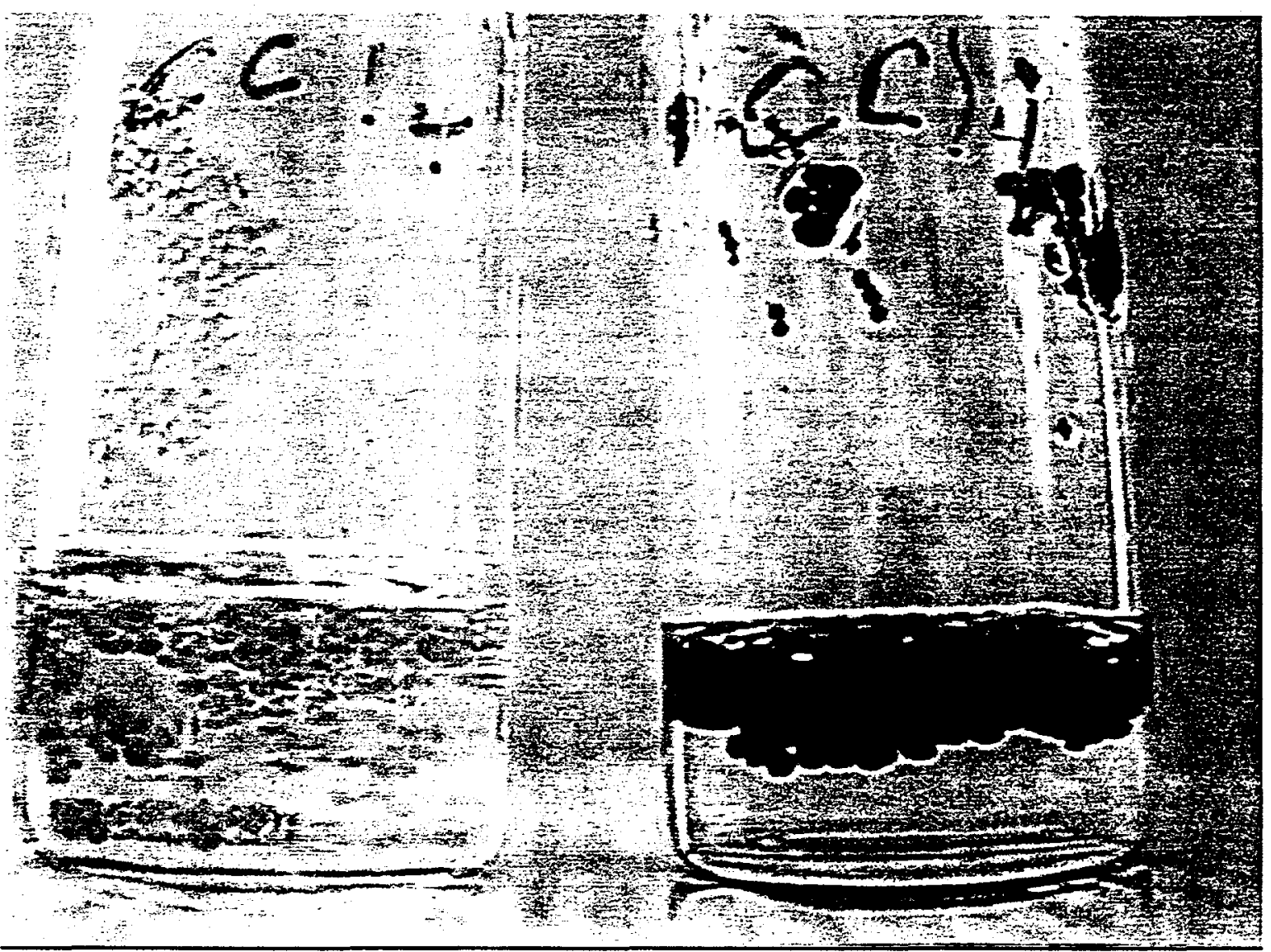

Figure 6. Purolite NRW-400 anion exchange resin (left), and NRW-100 cation exchange resin (right) in Carbon Tetrachloride. 


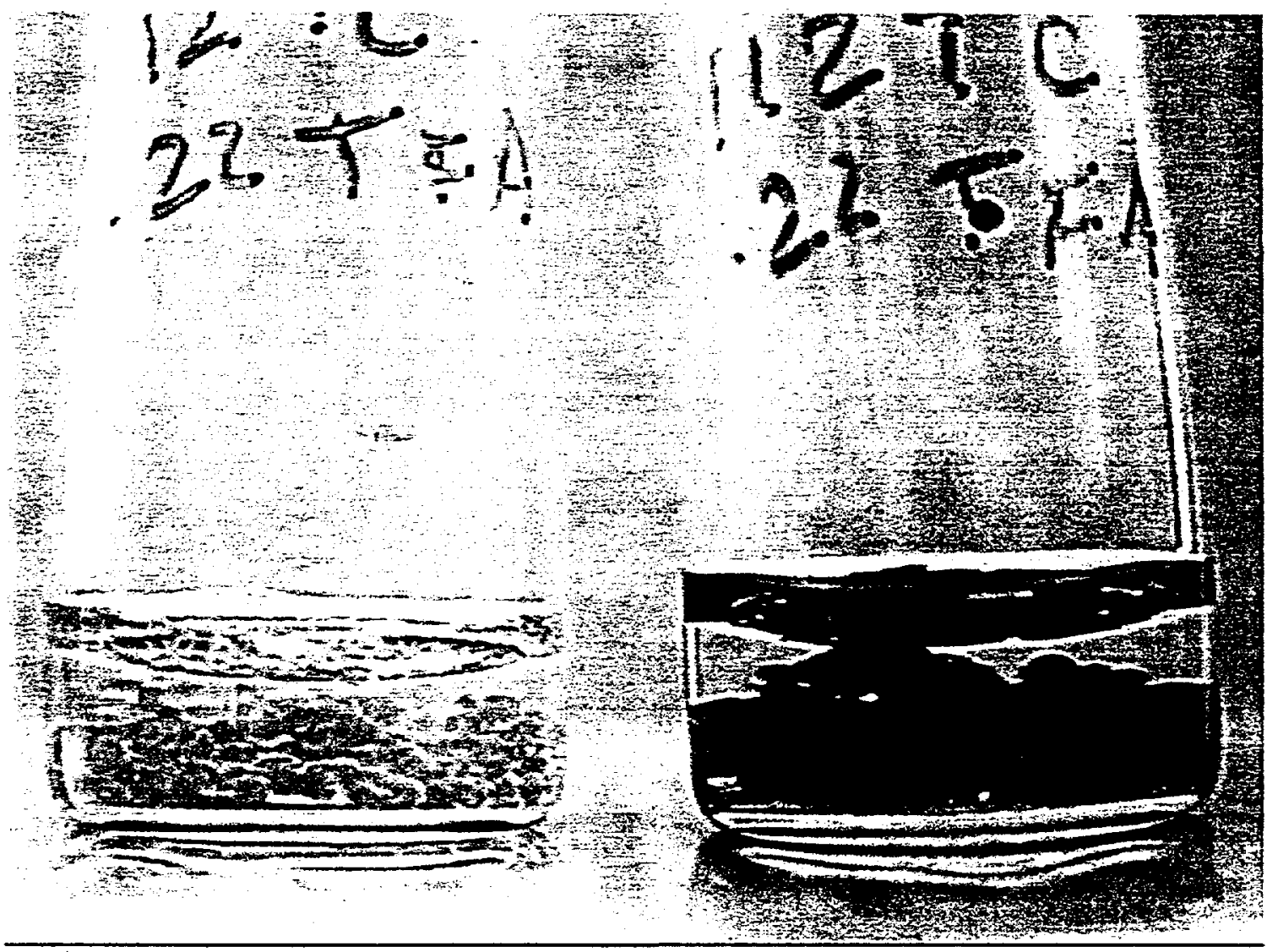

Figure 7. Purolite NRW-400 anion exchange resin (left), and NRW-100 cation exchange resin (right) in 1,1,2-Trichloro-1,2,2-trifluoroethane. 


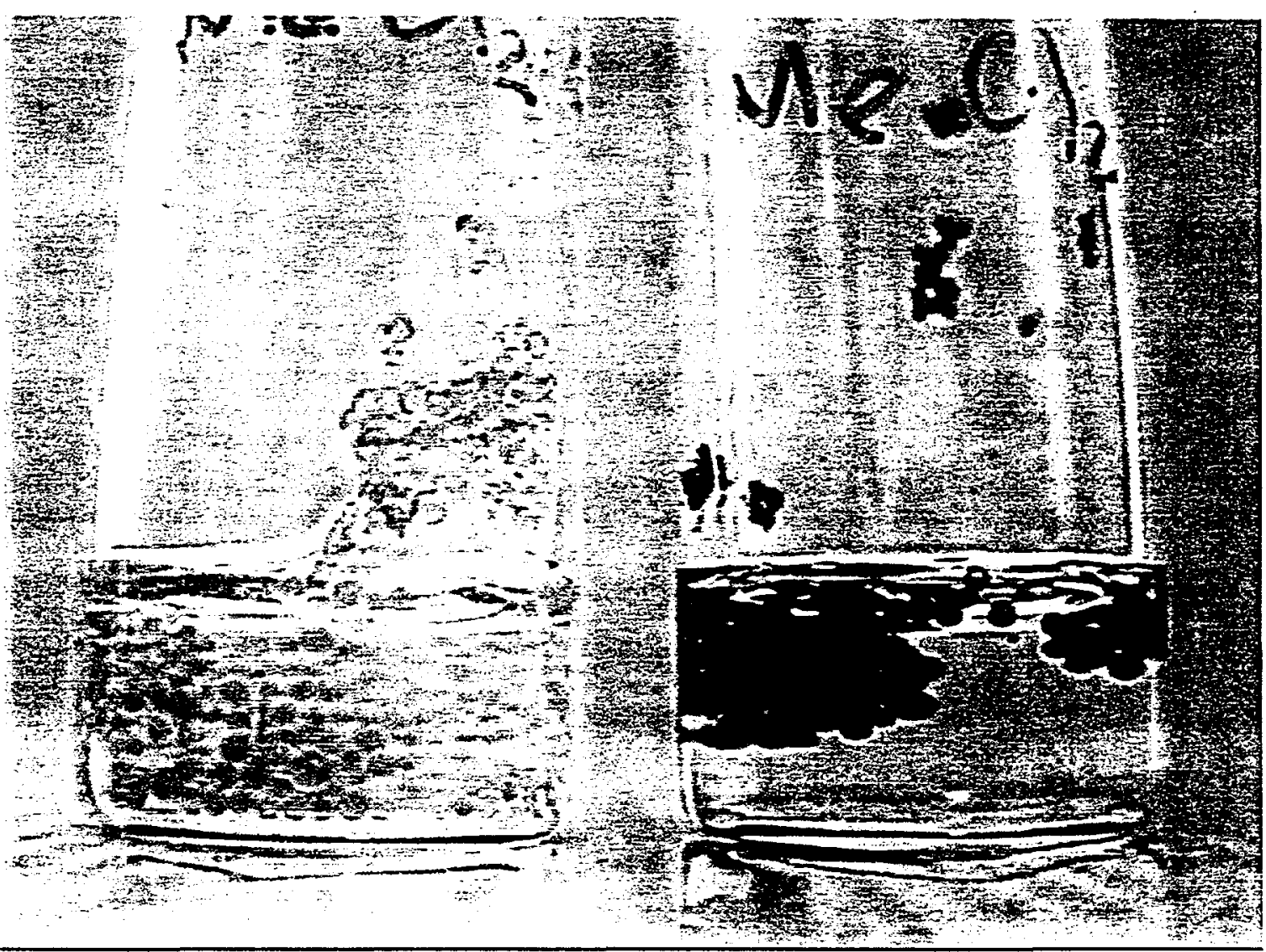

Figure 8. Purolite NRW-400 anion exchange resin (left), and NRW-100 cation exchange resin (right) in Methylene Chloride. 


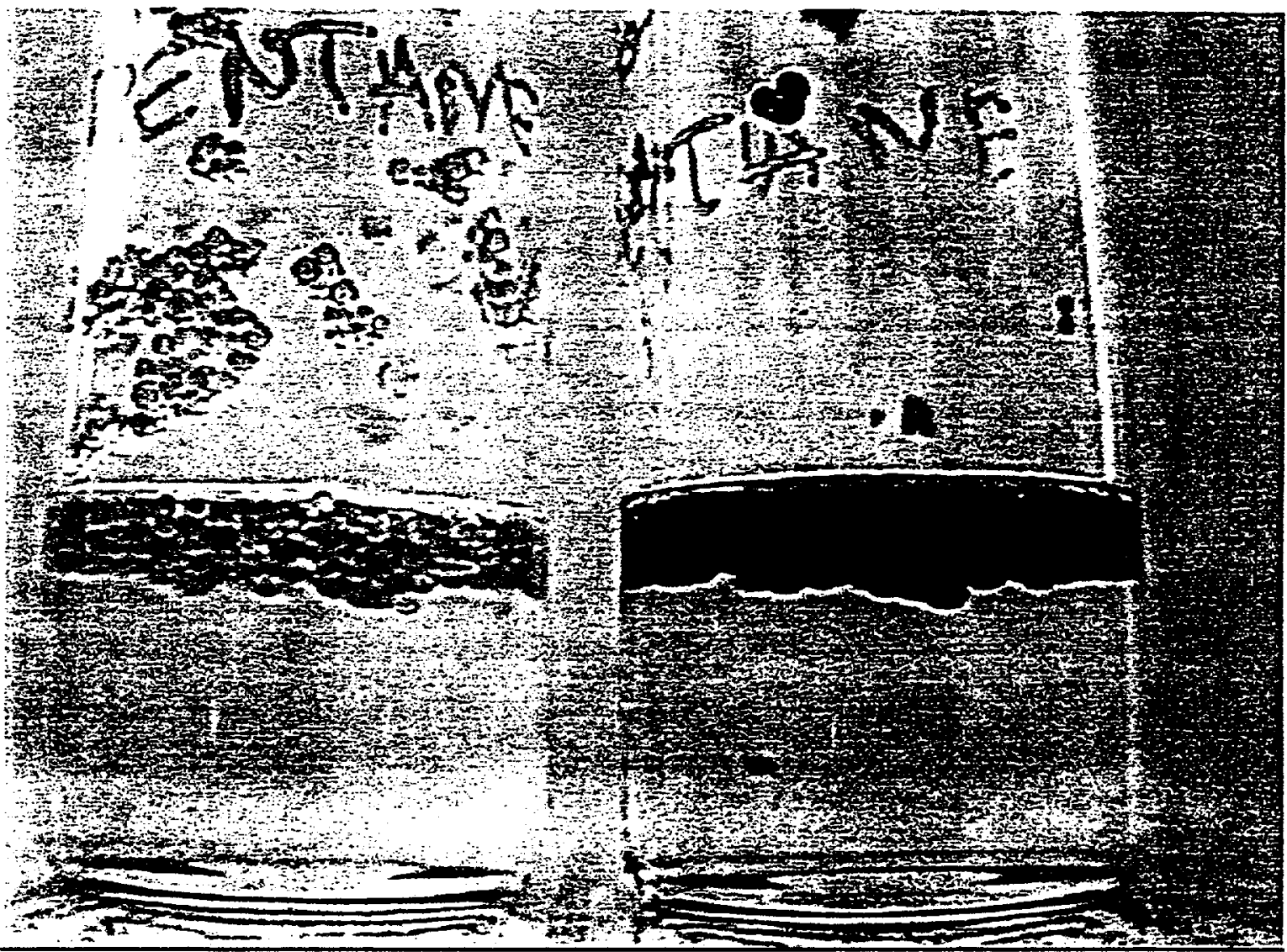

Figure 9. Purolite NRW-400 anion exchange resin (left), and NRW-100 cation exchange resin (right) in pentane. Both the anion and cation beads are relatively unaffected. 


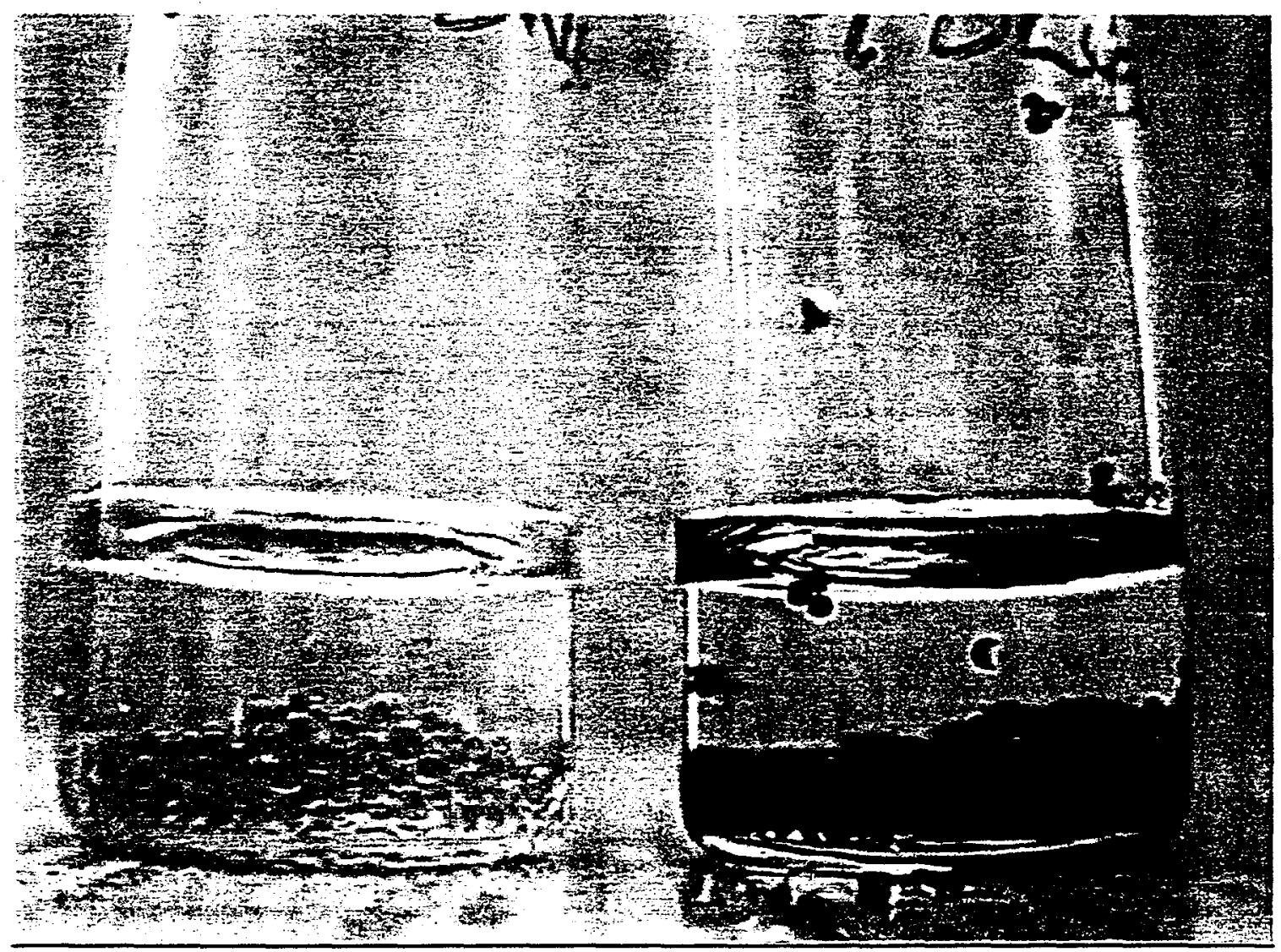

Figure 10. Purolite NRW-400 anion exchange resin (left), and NRW-100 cation exchange resin (right) in toluene. Note some degree of swelling relative to pentane contacted beads. 


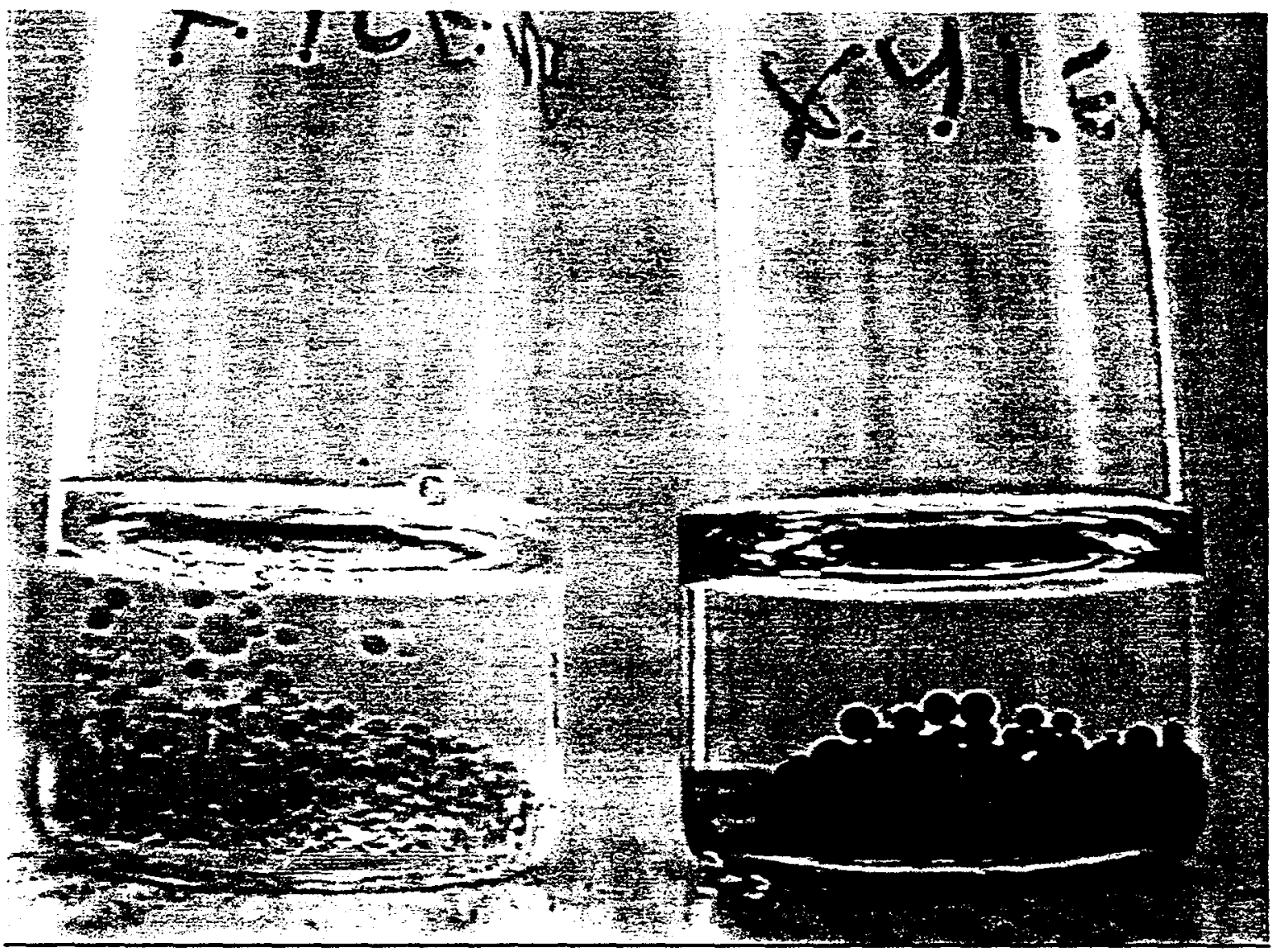

Figure 11. Purolite NRW-400 anion exchange resin (left), and NRW-100 cation exchange resin (right) in xylenes. Note degree of swelling and colored solution in the cation beads. 

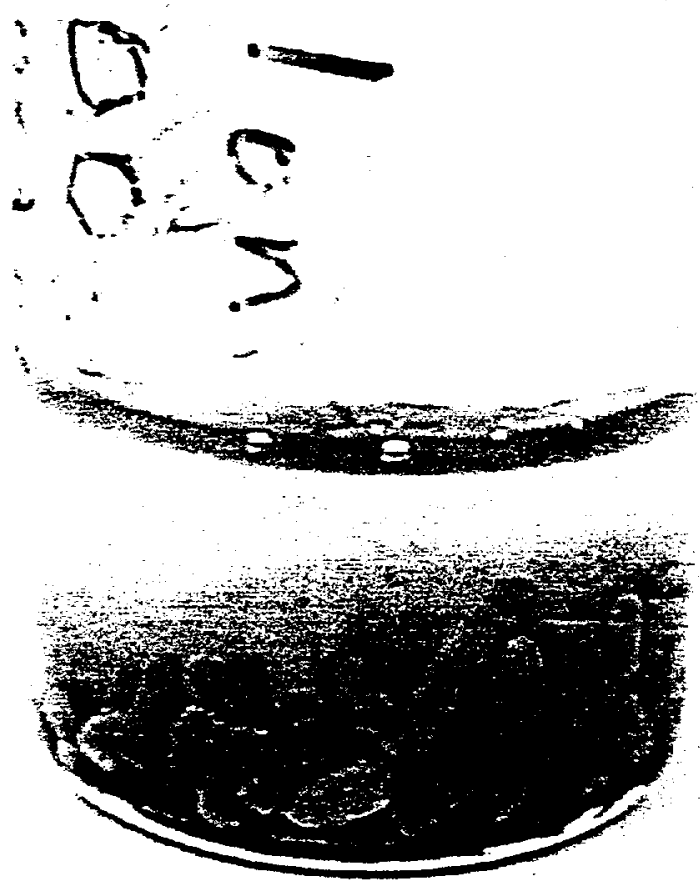

Figure 12. Zeolon-900 in deionized water. Note the suspended fines. 


\section{Experimental}

\section{Solvent/Purlolite Interaction Evaluation}

Five hundred milligram samples of Purolite NRW-400 anion exchange resin and NRW-100 cation exchange resin were each contacted separately with seven different solvents. Relatively nonpolar solvents were selected based on the nonpolar nature of polystyrene, the backbone of both Purolite resins. Since no published solubility parameter could be found for polystyrene, a group of solvents with a wide range of solubility parameters were chosen (Table 2). The solubility parameter is a physical constant used to describe the relationship between the physical properties of the solvent and its effectiveness in dissolving specific solutes (Riddick et al. 1986). Solubility is generally higher if both the solvent and the solute have similar solubility parameters. Figures 5 through 11 show both Purolite resin bead types (NRW-100 and NRW-400) in the various solvents.

Table 2. Solvents Evaluated for Extraction Effectiveness

\begin{tabular}{|l|l|}
\hline Solvent & Solubility Parameter \\
\hline Pentane & 7.0 \\
\hline $1,1,2-$ Trichloro-1,2,2-Trifluoroethane & 7.2 \\
\hline $1,1,1-$ Trichloroethane & 8.5 \\
\hline Carbon Tetrachloride & 8.6 \\
\hline Xylenes & 8.8 \\
\hline Toluene & 8.9 \\
\hline Methylene Chloride & 9.9 \\
\hline
\end{tabular}

\section{Inorganic Ion Exchanger (Zeolon-900) Behavior in Water}

A small quantity of Zeolon- 900 was placed in a beaker of deionized water and stirred on a stir plate at low to medium speed for approximately 12 hours. A second sample was place in a $20-\mathrm{mL}$ vial with deionized water and left at room temperature for several days. Figure 12 shows Zeolon- 900 extrudate in the $20-\mathrm{mL}$ vial with fines suspended in the water. The stirred sample formed a muddy silt on the bottom of the beaker. Given the general shape and color of the Zeolon- 900 and its poor mechanical stability, this ion exchange material clearly is not the round bead material observed in samples collected from K East Basin. While no Zeolon-900 extrudates were found during sieving of $\mathrm{K}$ Basins sludge, the results from the laboratory testing show that the Zeolon disintegrates, which corroborates the lack of extrudates observed.

\section{Discussion}

The goal of the work was to identify an effective solvent for dissolving the Purolite resin beads for PCB extraction. The potential effectiveness of the solvents for extraction of PCBs was judged by the degree of bead dissolution and swelling observed. Complete dissolution was not expected due to the high level of crosslinking in the polymer. As shown in Figures 6 through 12, no beads were significantly dissolved by the solvents tested, but swelling did occur.

The differences in bead swelling were small but distinct. Pentane had no appreciable effect on either the anionic or cation bead materials. The remainder of the solvents appeared to cause some degree of bead swelling. Xylenes appeared to cause a slightly greater degree of bead swelling than the other solvents. This 
higher degree of swelling indicates more interaction; therefore, xylenes may be a good candidate for PCB extraction.

Because the resin beads are organic and have a high surface area for adsorption, both internally and externally, the Purolite could be the primary PCB carrier in K Basin sludge. Although PCBs were not detected in the floor sample (KES-H-08), PCBs may have dispersed through the basin before the beads were spilled, or a localized release of PCB could have occurred in an area away from where KES-H-08 was taken. The question of whether or not PCBs are associated with one component of the floor sludge to a greater degree than the rest has implication for the treatment and removal strategies ultimately selected. Factors other than their affinity for PCBs may also underlie the need to selectively remove the beads from $\mathrm{K}$ Basin. These factors include the formation of reactive/explosive compounds during nitric acid dissolution, i.e., nitro organics, and the potential high affinity of anion resin bead for plutonium under acid conditions (Delegard et al. 1997).

Potential methods for removing the beads include wet sieving and density gradient centrifugation (although several other concepts could also be considered). Wet sieving removes a fraction of the beads from the other sludge components; however, the amount of beads remaining in the sludge after sieving is not known.

Density gradient centrifugation may provide a more complete separation of the beads (and possibly other sludge components as well) (Work and Work 1982). An aqueous density gradient in the range of 1 to 3.5 $\mathrm{g} / \mathrm{mL}$ can be prepared from cesium bromide. Since the separation is performed in an aqueous media, it is unlikely that any significant redistribution of the PCBs will occur. It is expected that a density gradient centrifugation separation will allow the anion and cation beads to be completely separated from one another, as well as from the other components of the floor sludge.

The Zeolon-900 extrudate appears friable enough to disintegrate into fines with minimal mechanical energy. It is logical to expect that any Zeolon- 900 found in the K-Basin floor sludge would be in the form of fines. However, selectively removing the Zeolon is not a likely option since it is intimately mixed with the sludge.

\section{References}

Delegard, C. H., 1998. "K Basin Sludge Materials Treatment Testing Strategy." HNF-1926 Rev. 0, Duke Engineering Services Hanford, Richland, Washington.

Fluor Daniel Hanford, Inc., 1997. "Recommended Strategy for Disposal of K Basins Sludge." Letter Report to J. D. Wagoner, U.S. Department of Energy, June 30, 1997. FDH-9755700, Richland, Washington.

Gerber, M. S., June 1996. "The Plutonium Production Story at the Hanford Site: Processes and Facilities History." WHC-MR-0521, Rev. 0. Westinghouse Hanford Company, Richland, Washington.

Harland, C. E., Ed. 1994. Ion Exchange: Theory and Practice, $2^{\text {nd }}$ Edition. Royal Society of Chemistry.

Makenas, B. J., T. L. Welsh, R. B. Baker, D. R. Hansen, and G. R. Golcar. 1996. "Analysis of Sludge from Hanford K East Basin Floor and Weasel Pit." WHC-SP-1182, Westinghouse Hanford Company, Richland, Washington.

Makenas, B. J., T.L. Welsh, R. B. Baker, E. W. Hoppe, A. J. Schmidt, J. Abrefah, J. M. Tingey, P. R. Bredt, and G. R. Golcar. 1997. "Analysis of Sludge from Hanford K East Basin Canisters." HNF-SP-1201, DE\&S Hanford, Inc., Richland, Washington.

Packer, M. J. 1998. "K Basins Sludge Inventory Composition." HNF-SD-TI-053, Rev. 0. Duke Engineering Services Hanford, Richland, Washington. 
Papp, I. G. 1997. "Evaluation to Disposition Components of K Basin Fuel Sludge." HNF-SD-SNF-ES-024, Rev. 0, Numatec Hanford Corporation, Richland, Washington.

Pitner, A. L. March 1995. "KE Basin Underwater Visual Fuel Survey." WHC-SD-SNF-TI-012, Rev. 0, Westinghouse Hanford Company, Richland, Washington.

Pool, K. H., and G. M. Mong. 1997. "Feasibility Study of Chemical Alternative for Simulated K Basin Sludge.” DESH-9754549, Letter Report to DE\&S Hanford, Inc., June 27, 1997. Pacific Northwest National Laboratory, Richland, Washington.

Riddick, J. A., W. B. Bunger, and T. K. Sakano. 1986. Organic Solvents-Physical Properties and Methods of Purification, $4^{\text {th }}$ Edition, Vol. II. John Wiley \& Sons.

Silvers, K. L., 1997. "Wet Sieving of K-East Floor and Weasel Pit Sludge." 28507-01, Letter Report to R. P. Omberg, DE\&S Hanford, Inc., November 6, 1997. Pacific Northwest National Laboratory, Richland, Washington.

Sengupta, A. K., Ed. 1995. Ion Exchange Technology. Technomic Publishing.

Work, T. S., and E. Work, Eds. 1982. Laboratory Techniques in Biochemistry and Molecular Biology, Vol. 6. Elsevier. 